Revista Brasileira de Agricultura Irrigada v.7, nº 5, p. 277 - 289, 2013

ISSN 1982-7679 (On-line)

Fortaleza, CE, INOVAGRI - http://www.inovagri.org.br

DOI: $10.7127 /$ rbai.v7n500174

Protocolo 174.13 - 13/08/2013 Aprovado em 22/10/2013

\title{
BIOMETRIA DO GIRASSOL EM FUNÇÃO DA SALINIDADE DA ÁGUA DE IRRIGAÇÃO E DA ADUBAÇÃO NITROGENADA ${ }^{1}$
}

\author{
Doroteu Honório Guedes Filho ${ }^{2}$; João Batista dos Santos ${ }^{3}$; Hans Raj Gheyi ${ }^{4}$; \\ Lourival Ferreira Cavalcante ${ }^{5}$; Hélio Leodelgario de Farias ${ }^{6}$
}

\begin{abstract}
RESUMO
O cultivo do girassol irrigado nas áreas semiáridas evidencia a necessidade de informações a respeito de suas respostas à qualidade da água de irrigação simultaneamente com o manejo da adubação que possibilite incrementos dos índices de produtividade. Nesse contexto, o presente experimento foi conduzido, no período de novembro de 2011 a fevereiro de 2012, em condições de campo, no município de Remígio, Paraíba, com o objetivo de avaliar o crescimento de plantas de girassol (Helianthus annuus L.) cv. EMBRAPA 122 V-2000, submetidas a níveis de salinidade da água de irrigação e a doses de nitrogênio. Os tratamentos foram distribuídos em blocos casualizados, com três repetições e 30 plantas por parcela, usando o esquema fatorial $5 \times 4$, referente a cinco níveis de salinidade da água de irrigação $\left(0,15 ; 1,5 ; 2,5 ; 3,5 \mathrm{e}_{4,5} \mathrm{dS} \mathrm{m}^{-1}\right)$ e a quatro doses de nitrogênio de $\left(40,60,80 \mathrm{e} 100 \mathrm{~kg} \mathrm{ha}^{-1}\right)$. O aumento da salinidade da água de irrigação para níveis acima de $0,15 \mathrm{dS} \mathrm{m}^{-1}$ afetou negativamente o crescimento do girassol, em altura, diâmetro caulinar, número de folhas e área foliar, mas foi afetado pelo aumento das doses de nitrogênio, enquanto que a interação foi significativa apenas para a variável área foliar aos 15 dias após emergência. Dentre as variáveis avaliadas, a área foliar do girassol é a mais comprometida com o aumento do teor salino das águas.
\end{abstract}

Palavras-chave: Helianthus annuus L., condutividade elétrica, nitrogênio.

\footnotetext{
${ }^{1}$ Trabalho financiado com recursos do PNPD/CAPES

${ }^{2}$ Doutorando em Engenharia Agrícola/UAEAg/UFCG/Campina Grande, PB, Email:

doroteufilho@hotmail.com

${ }^{3}$ Doutor em Ciências, Bolsista PNPD/CAPES/UAEAg/UFCG, Campina Grande, PB, Email: agrosantos@hotmail.com

${ }^{4}$ Departamento de Eng. Agrícola, CTRN/UFCG, atualmente Professor Visitante UFRB, Email hans@pq.cnpq.br

${ }^{5} \mathrm{CCA} / \mathrm{UFPB} / \mathrm{Campus} \mathrm{II,} \mathrm{Areia,} \mathrm{PB,} \mathrm{Email} \mathrm{lofeca@cca.ufpb.br}$

${ }^{6}$ Graduando em Agronomia, CCA/UFPB/Campus II, Areia, PB, Email: heliojtm@ hotmail.com
} 


\title{
BIOMETRY OF SUNFLOWER AS AFFECTED BY SALINITY OF IRRIGATION WATER AND NITROGEN FERTILIZATION
}

\begin{abstract}
The cultivation of irrigated sunflower in semiarid areas highlights the need for information about its response to the quality of irrigation water simultaneously with fertilizer management that allows increments of productivity indices. In this context, the present experiment was conducted during November 2011 to February 2012 under field conditions in the municipality of Remígio, Paraíba, with the objective to evaluate the growth of sunflower (Helianthus annuus L.) cv. EMBRAPA 122 V-2000, subjected to salinity levels of irrigation water and nitrogen. Treatments were arranged in a randomized block design with three replications and 30 plants per plot, using a $5 \times 4$ factorial arrangement with irrigation water salinity levels of $0.15,1.5,2.5,3.5$ and $4.5 \mathrm{dS} \mathrm{m}^{-1}$ and nitrogen rates of 40,60, 80 and $100 \mathrm{~kg} \mathrm{ha}^{-1}$. The increase in water salinity above $0.15 \mathrm{dS}$ $\mathrm{m}^{-1}$ affected negatively the growth in height, stem diameter, number of leaves and leaf area of sunflower, but increasing doses of nitrogen stimulated them, while the interactive effect was significant only for the leaf area at 15 days after emergence. Among the variables evaluated the leaf area of sunflower is more sensitive to increasing salt content of the water.
\end{abstract}

Keywords: Helianthus annus L., electrical conductivity, nitrogen.

\section{INTRODUÇÃO}

O girassol (Helianthus annuus L.) é uma dicotiledônea anual que se adapta a diversas condições edafoclimáticas, sendo cultivado em todos os continentes, exercendo elevada importância na economia mundial. Atualmente, é utilizado na alimentação humana, ração de animais domésticos, ornamentação e na produção de biocombustíveis (MORGADO et al., 2002).

Apesar da importância do girassol no contexto atual brasileiro e da sua adaptação aos mais variados tipos de solo e clima, o sucesso do seu cultivo nas áreas semiáridas, a exemplo de muitas outras culturas, estar condicionado ao uso da tecnologia da irrigação (OLIVEIRA et al., 2010). Logo, trabalhos voltados para o estudo do efeito da salinidade da água devem ser conduzidos, visto que a salinidade pode prejudicar o crescimento e a produção de muitas plantas não alimentícias como mamona - Ricinus comunis, nim - Azadirachta indica (FREIRE et al., 2010), noni - Morinda citrifolia (NIVAS et al., 2011), pinhão manso - Jatropha curcas (Cavalcante et al., 2011) e inclusive o girassol (SILVA et al., 2009; NOBRE et al., 2010) que, conforme Ayers e Westcot (1999) é moderadamente tolerante aos sais.

Os efeitos dos sais sobre as plantas podem ser refletidos na diminuição da absorção de água, toxicidade de íons específicos e pela interferência dos sais nos processos fisiológicos comprometendo o crescimento e o desenvolvimento das plantas. No solo, os efeitos 
negativos da salinização e sodificação são desestruturação, aumento da densidade aparente e da retenção de água, redução da infiltração de água pelo excesso de íons sódicos e diminuição da fertilidade (RHOADES et al., 2000). O aumento do teor salino da água ou do solo baixa o potencial osmótico da solução reduzindo a disponibilidade de água e nutrientes às plantas (RICHARDS, 1954; MARSCHNER, 2005). Nas plantas, a intensidade desses efeitos depende de outros fatores, tais como: espécie, cultivar, estádio fenológico da cultura, tipos dos sais, intensidade e duração do estresse salino, manejo cultural, qualidade da água de irrigação e condições edafoclimáticas (TESTER e DAVENPORT, 2003; ASHRAF e HARRIS, 2004; MUNNS e TESTER, 2008).

Nas atividades agrícolas, os efeitos da salinidade do solo não são restritos apenas à qualidade das águas de irrigação ou à natureza mineralógica do solo. Há casos também na literatura sobre a importância da interação da salinidade da água com a adubação mineral, tanto nos aspectos da elevação do teor salino no solo, como na atenuação dos efeitos dos sais da água ou do solo às plantas. Nesse contexto, o nitrogênio que promove o crescimento e está contido em moléculas de substâncias vitais como aminoácidos, vitaminas, enzimas, coenzimas das plantas (FLORES et al., 2001), pode contribuir para a redução dos efeitos da salinidade nas plantas sensíveis e moderadamente sensíveis. Esse nutriente desempenha importante função no metabolismo e na nutrição da cultura do girassol; sua deficiência pode causar desordem nutricional com queda na produção e o excesso prejudica o rendimento de óleo (BISCARO et al., 2008).

O girassol apresenta características viáveis economicamente do ponto de vista agronômico, como ciclo curto, qualidade de semente e quantidade de óleo produzido. Essas características evidenciam a possibilidade de aumento da renda dos produtores, sobretudo após a decisão do governo brasileiro de introduzir o biodiesel na matriz energética nacional, com a adição de óleo extraído de algumas plantas ao óleo diesel comercial (SILVA et al., 2007).

Pela importância do girassol no Programa Nacional de Biocombustíveis, sistemas de cultivo desta oleaginosa em áreas semiáridas do Nordeste exigem estratégias de manejo a partir da interação salinidade $\mathrm{x}$ fertilidade do solo. $\mathrm{E}$ dentre as estratégias de manejo, encontra-se aquela que deve ter como meta a mitigação dos efeitos danosos dos sais das águas de irrigação à maioria das culturas nas áreas semiáridas.

Diante do exposto, o presente trabalho teve como objetivo, avaliar o crescimento do girassol em função da salinidade da água de irrigação e da adubação nitrogenada.

\section{MATERIAL E MÉTODOS}

O experimento foi realizado em condições de campo, durante o período de 10 de novembro de 2011 a 15 de fevereiro de 2012, no Sítio Macaquinhos, localizado a $8 \mathrm{~km}$ ao Sul do 
município de Remígio, Estado da Paraíba. O município pertence à microrregião do Curimataú Ocidental e situa-se nas coordenadas geográficas $6^{\circ} 53^{\prime} 00^{\prime \prime} \mathrm{S}$ e $36^{\circ} 02^{\circ} 00^{\prime \prime} \mathrm{W}$, com altitude média de $470 \mathrm{~m}$.

O solo da área experimental é classificado como Neossolo Quartzarênico Eutrófico e apresenta as seguintes características químicas na camada de 0 a $20 \mathrm{~cm}$ de profundidade: $\mathrm{pH}$ $\left(\mathrm{em} \mathrm{H}_{2} \mathrm{O}\right)=6,89 ; \mathrm{P}=5 \mathrm{mg} \mathrm{dm}{ }^{-3} ; \mathrm{K}=2,17 \mathrm{mg}$ $\mathrm{dm}^{-3} ; \mathrm{H}+\mathrm{Al}^{+3}=0,80 \mathrm{cmol}_{\mathrm{c}} \mathrm{kg}^{-1} ; \mathrm{Ca}^{+2}=0,25$ $\mathrm{cmol}_{\mathrm{c}} \mathrm{kg}^{-1} ; \mathrm{Mg}^{+2}=2,30 \mathrm{cmol}_{\mathrm{c}} \mathrm{kg}^{-1} ; \mathrm{Na}^{+}=0,02$ $\mathrm{cmol}_{\mathrm{c}} \mathrm{kg}^{-1}$; e o esterco bovino utilizado na adubação do solo do experimento apresentava: $\mathrm{pH}\left(\mathrm{em} \mathrm{H}_{2} \mathrm{O}\right)=8,76 ; \mathrm{P}=5,47 \mathrm{mg} \mathrm{dm}^{-3} ; \mathrm{K}=$ $10,25 \mathrm{mg} \mathrm{dm}{ }^{-3} ; \mathrm{H}+\mathrm{Al}^{+3}=0 ; \mathrm{Ca}^{+2}=8,80 \mathrm{cmol}_{\mathrm{c}}$ $\mathrm{kg}^{-1} ; \mathrm{Mg}^{+2}=13,34 \mathrm{cmol}_{\mathrm{c}} \mathrm{kg}^{-1} ; \mathrm{Na}^{+}=2,47 \mathrm{cmol}_{\mathrm{c}}$ $\mathrm{kg}^{-1}$, de acordo com a metodologia da EMBRAPA (1997).

Os tratamentos foram distribuídos no esquema fatorial $5 \times 4$, referente a cinco níveis de salinidade da água de irrigação $(0,15 ; 1,5 ; 2,5$;

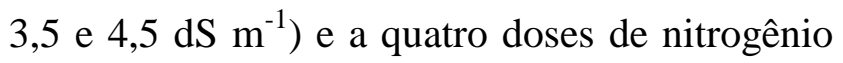
$\left(40,60,80\right.$ e $\left.100 \mathrm{~kg} \mathrm{ha}^{-1}\right)$. Os tratamentos foram distribuídos em blocos casualizados, com três repetições, tendo 30 plantas por parcela experimental, no espaçamento de 0,40 m entre plantas e de 1,0 m entre linhas. Cada parcela experimental dispunha de uma área de $12 \mathrm{~m}^{2}$ $(4,0 \times 3,0 \mathrm{~m})$. A variedade de girassol utilizada no experimento foi a cv. EMBRAPA $122 \mathrm{~V}-$ 2000, cujas sementes foram fornecidas pela EMBRAPA Soja, Londrina-Paraná.
O preparo da área constou de três gradagens, sendo duas aradora na profundidade de $30 \mathrm{~cm}$ e uma niveladora. Em seguida foram incorporados nos sulcos de plantio, 30 dias antes do semeio, $15 \mathrm{~kg}$ de esterco bovino por parcela experimental, juntamente com $80 \mathrm{~kg} \mathrm{ha}^{-1}$ de $\mathrm{P}_{2} \mathrm{O}_{5}$ e $2 \mathrm{~kg} \mathrm{ha}^{-1}$ de boro, respectivamente na forma superfosfato simples e ácido bórico.

A adubação nitrogenada foi aplicada conforme os tratamentos, sendo a uréia o fertilizante utilizado; e a potássica correspondeu a $80 \mathrm{~kg} \mathrm{ha}^{-1}$ de $\mathrm{K}_{2} \mathrm{O}$ e utilizou-se como fonte o fertilizante cloreto de potássio; a dose de $\mathrm{K}_{2} \mathrm{O}$ foi parcelada em três vezes, sendo um terço aplicado no sulco de plantio antes da semeadura e dois terços aplicados em cobertura (divididos em duas parcelas iguais e aplicadas aos 20 e 40 dias após emergência). As adubações de coberturas foram aplicadas em sulcos abertos a uma distância de aproximadamente $10 \mathrm{~cm}$ das plantas e, em seguida, incorporou-se o adubo ao solo.

No preparo dos níveis de salinidade das águas se utilizou $\mathrm{NaCl}$ adicionado à água proveniente de um açude localizado próximo ao local do experimento, de acordo com os tratamentos, sendo que as quantidades utilizadas no preparo das águas de irrigação foram determinadas conforme Rhoades et al. (2000), de forma a se obter a CEa do respectivo tratamento, conferindo-se o seu valor com auxílio de um condutivímetro portátil. A irrigação foi realizada a cada dois dias, por meio de um sistema de irrigação localizada, usando fita gotejadora com 
vazão de $6,0 \mathrm{~L} \mathrm{~h}^{-1}$. A lâmina de água de irrigação foi calculada com base no $\mathrm{Kc}$ da cultura (DOORENBOS e KASSAM, 1994) e a evapotranspiração de referência (ETo), estimada pelo método do tanque classe $\mathrm{A}$, instalado na estação meteorológica da UFPB, campus II, Areia-PB, localizada à $8 \mathrm{~km}$ de distância em linha reta da área experimental.

A semeadura foi realizada manualmente colocando-se oito sementes por cova. Aos 10 dias após emergência (DAE) realizou-se o primeiro desbaste deixando três plântulas por cova e o segundo aos 15 DAE mantendo uma planta por cova (a mais vigorosa). Aos 30 DAE foram realizadas uma capina para controlar as plantas daninhas e uma pulverização com inseticida (Provado $200 \mathrm{Sc}$ ) na dosagem de 0,35 $\mathrm{L} \mathrm{ha}^{-1}$ (diluído em 100 L de água), para controle da mosca branca (Bemisia tabaci).

As avaliações foram realizadas quinzenalmente em duas plantas por parcelas (sempre nas mesmas plantas) aos 15, 30, 45, 60 e 75 DAE. Foram determinados a altura de plantas, com trena milimetrada, o diâmetro caulinar, usando paquímetro digital de precisão 1:50, a contagem do número de folhas e o cálculo da área foliar, pelo método não destrutivo, empregando a metodologia proposta por Maldaner et al. (2009) utilizando a expressão: $\mathrm{AF}=0,1328 \times \mathrm{C}^{2,5569}$, em que: $\mathrm{AF}$ é a área foliar e $\mathrm{C}$ é o comprimento da nervura central das folhas de cada planta.

Os dados obtidos foram avaliados mediante análise de variância pelo teste ' $\mathrm{F}$ ' ao nível de 0,01 e 0,05 de probabilidade e nos casos de efeitos significativos, realizou-se análise de regressão polinomial utilizando o software estatístico SISVAR-ESAL (Lavras, MG) (FERREIRA, 2003).

\section{RESULTADOS E DISCUSSÃO}

De acordo com análise de variância os efeitos isolados dos fatores salinidade da água de irrigação no diâmetro do caule aos 60 e 75 DAE e na altura de plantas aos 45, 60 e 75 DAE foram significativos $(\mathrm{p}<0,05)$, enquanto que a adubação nitrogenada exerceu efeito significativo em todas as épocas com exceção da altura de plantas aos 30 DAE (Tabela 1). A interação entre a salinidade da água de irrigação e doses de nitrogênio não exerceu efeitos significativos sobre o crescimento do girassol avaliado pelo diâmetro caulinar e pela altura das plantas, em nenhum período de avaliação, indicando que as plantas irrigadas com diferentes CE da água de irrigação tiveram comportamento semelhante quando foram submetidas as diferentes doses de nitrogênio. 
Tabela 1. Resumo da análise de variância para diâmetro caulinar e altura de plantas de girassol, aos 15, 30, 45, 60 e 75 dias após a emergência (DAE), em função da salinidade da água de irrigação e da adubação nitrogenada

\begin{tabular}{|c|c|c|c|c|c|}
\hline \multirow{3}{*}{$\begin{array}{l}\text { Fonte de } \\
\text { Variação }\end{array}$} & \multicolumn{5}{|c|}{ Quadrados Médios } \\
\hline & \multicolumn{5}{|c|}{ Dias após a emergência (DAE) } \\
\hline & 15 & 30 & 45 & 60 & 75 \\
\hline \multicolumn{6}{|c|}{ Diâmetro de caule } \\
\hline Salinidade (S) & $1,279^{\mathrm{ns}}$ & $12,520^{\mathrm{ns}}$ & $25,532^{\mathrm{ns}}$ & $43,528^{*}$ & $44,309^{*}$ \\
\hline Reg. Linear & - & - & - & $127,723^{* *}$ & $129,979^{* *}$ \\
\hline Resíduo 1 & 0,631 & 3,913 & 7,149 & 9,629 & 9,568 \\
\hline Nitrogênio (N) & $4,318^{* *}$ & $32,981^{* *}$ & $43,072^{* *}$ & $30,746^{* *}$ & $28,820^{*}$ \\
\hline Reg. Linear & $12,607^{* *}$ & $96,696^{* *}$ & $127,466^{* *}$ & $88,346^{* *}$ & $82,950^{* *}$ \\
\hline $\begin{array}{l}\text { Interação } \\
(\mathrm{S} \times \mathrm{N})\end{array}$ & $0,382^{\mathrm{ns}}$ & $1,663^{\text {ns }}$ & $10,098^{\mathrm{ns}}$ & $15,631^{\mathrm{ns}}$ & $15,332^{\mathrm{ns}}$ \\
\hline Resíduo 2 & 0,595 & 4,309 & 6,143 & 7,823 & 7,622 \\
\hline Blocos & $1,793^{\mathrm{ns}}$ & $9,773^{\mathrm{ns}}$ & $1,782^{\mathrm{ns}}$ & $0,857^{\mathrm{ns}}$ & $0,642^{\mathrm{ns}}$ \\
\hline $\mathrm{CV} 1 \quad(\%)$ & 17,56 & 14,13 & 12,77 & 13,88 & 13,86 \\
\hline CV 2 (\%) & 17,04 & 14,82 & 11,84 & 12,51 & 12,37 \\
\hline
\end{tabular}

\section{Altura de plantas}

Salinidade (S) $\quad 9,308^{\mathrm{ns}} \quad 127,341^{\mathrm{ns}} \quad 1151,410^{*} \quad 1848,129^{*} \quad 1786,233^{*}$ Reg. Linear $\quad$ - $\quad$ - $\quad 3716,530^{* *} 7071,812^{* *} 6851,489^{* *}$ $\begin{array}{llllll}\text { Resíduo } 1 & 18,335 & 147,624 & 209,172 & 366,522 & 338,767\end{array}$ Nitrogênio (N) $\quad 19,058^{*} \quad 287,691^{\mathrm{ns}} \quad 789,726^{* *} \quad 416,744^{*} \quad 390,281^{*}$ Reg. Linear $51,294^{* *} \quad-\quad 2288,040^{* *} 473,763^{*}$ Reg. Quadrática - $\quad$ - $\quad$ - $\quad$ - $\quad 601,666^{*} \quad 561,04^{*}$

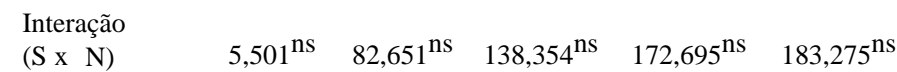
$\begin{array}{llllll}\text { Resíduo } 2 & 5,367 & 125,226 & 137,604 & 110,997 & 118,780\end{array}$ Blocos $\quad 12,585^{\mathrm{ns}} \quad 40,616^{\mathrm{ns}} \quad 227,329^{\mathrm{ns}} \quad 171,450^{\mathrm{ns}} \quad 147,387^{\mathrm{ns}}$ CV $1(\%) \quad 33,06 \quad 27,12 \quad 12,64 \quad 15,29 \quad 14,77$

\begin{tabular}{llllll} 
CV 2 (\%) & 17,89 & 24,98 & 10,25 & 8,41 & 8,75 \\
\hline
\end{tabular}

CV coeficiente de variação; ** significativo a $1 \%$ de probabilidade; * significativo a $5 \%$ de probabilidade; ns não significativo.

O diâmetro caulinar das plantas foi reduzido ao nível de 0,96 e 0,82 $\mathrm{mm}$ por aumento unitário da condutividade elétrica das águas de irrigação, aos 60 e 75 DAE (Figura
1A). Tendências decrescentes para diâmetro foram registradas também por Travassos et al. (2009) após irrigarem plantas de girassol (cv. EMBRAPA 122/V-2000) com águas salinas de 1 a $5 \mathrm{dS} \mathrm{m}^{-1}$ e registrarem decréscimos lineares de 0,15 e $0,62 \mathrm{~mm}$ no diâmetro caulinar aos 18 e 28 DAE, em condições de casa de vegetação utilizando vasos de $20 \mathrm{~L}$.

$\mathrm{O}$ aumento das doses de nitrogênio estimulou linearmente o crescimento em diâmetro do caule do girassol, avaliado aos 15, 30, 45, 60 e 75 DAE, com valores de 0,02; 0,06; 0,06; 0,05 e 0,06 mm por aumento unitário de doses de nitrogênio aplicada ao solo (Figura 1B). Resultados de aumento do diâmetro do caule do girassol foram constatados por Abbadi et al. (2008) ao avaliarem o suprimento de nitrogênio de 0,5 a $4 \mathrm{~g} \mathrm{vaso}^{-1}$ em ambiente protegido. Observa-se ainda nas Figuras 1A e 1B que aos 60 DAE o crescimento do diâmetro do caule é superior àquele observado aos 75 DAE. Essa redução no crescimento ocorre provavelmente devido à perda de água no processo fisiológico de maturação da planta de girassol.

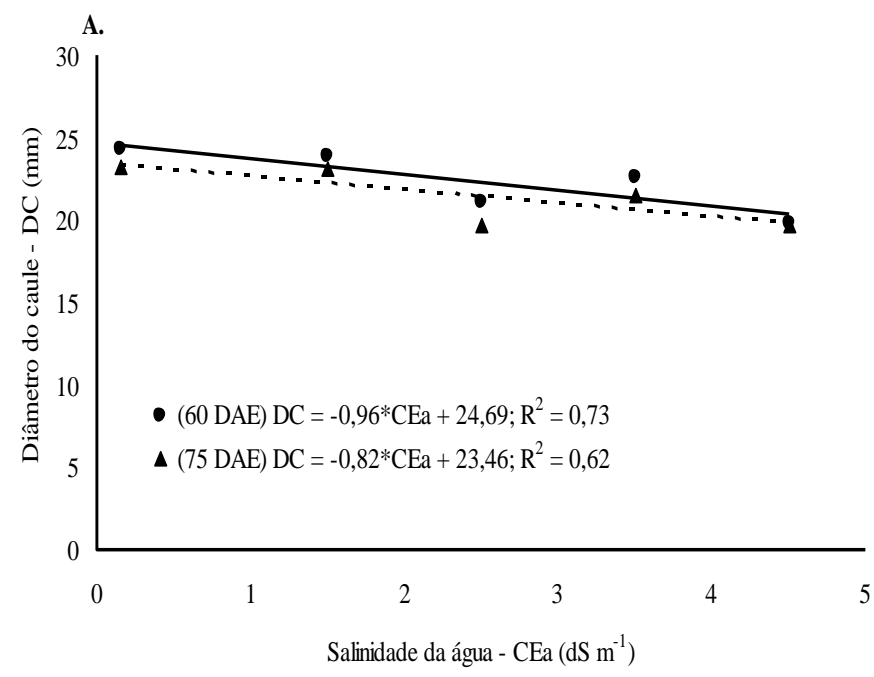




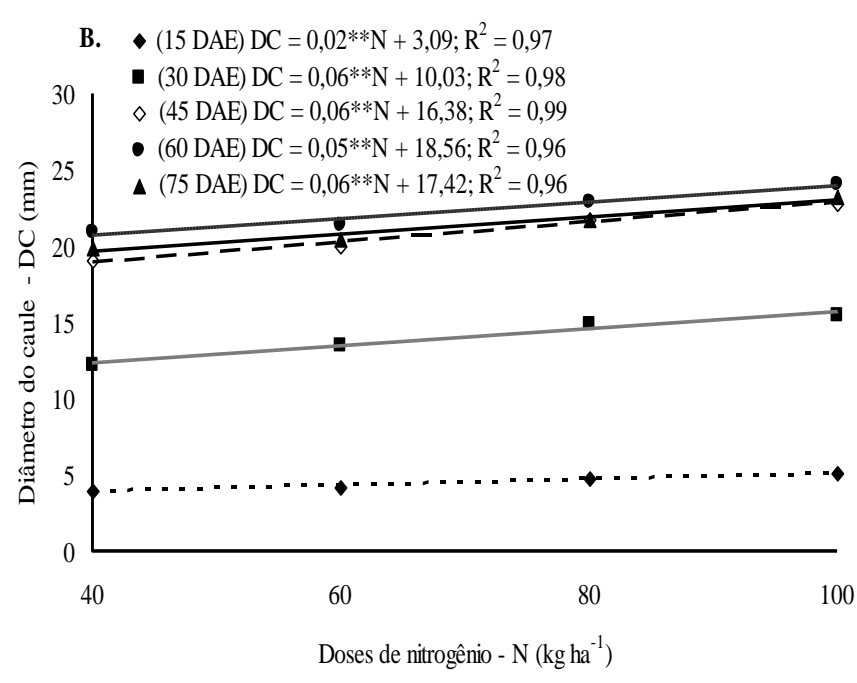

Figura 1. Diâmetro caulinar de girassol cv. EMBRAPA 122 V 2000 em função da salinidade da água de irrigação aos 60 e $75 \operatorname{DAE}$ (A) e da adubação nitrogenada aos 15, 30, 45, 60 e 75 DAE (B).

Assim como constatado para diâmetro do caule (aos 60 e 75 DAE), o crescimento das plantas em altura também foi reduzido linearmente com o aumento da salinidade nas proporções de 5,19; 7,16 e 7,05 cm, aos 45, 60 e 75 DAE, por aumento unitário da condutividade elétrica da água de irrigação (Figura 2A). Ao longo do ciclo da cultura, o aumento das doses de nitrogênio de 40 para 60 e $80 \mathrm{~kg} \mathrm{ha}^{-1}$ provocou inibição do crescimento das plantas, em altura, atingindo aos 60 e 75 DAE, basicamente o mais baixo valor $(121 \mathrm{~cm})$, nas doses estimadas de nitrogênio de 61,2 e $59,4 \mathrm{~kg}$ $\mathrm{ha}^{-1}$, respectivamente, e de aproximadamente 130 $\mathrm{cm}$ sob a dose $100 \mathrm{~kg} \mathrm{ha}^{-1}$ (Figura 2B). Os resultados encontrados, principalmente com relação aos primeiros dias, estão de acordo com aqueles obtidos por Fagundes et al. (2007) em estudo sobre os efeitos de doses de nitrogênio no desenvolvimento do girassol ornamental, quando registraram que as maiores doses de $\mathrm{N}$ proporcionaram também maior comprimento de caule. Por outro lado, divergem daqueles obtidos por Ivanoff et al. (2010), que concluíram que o aumento das doses de nitrogênio não estimularam o crescimento das plantas, em altura, aos 40 dias após a emergência.
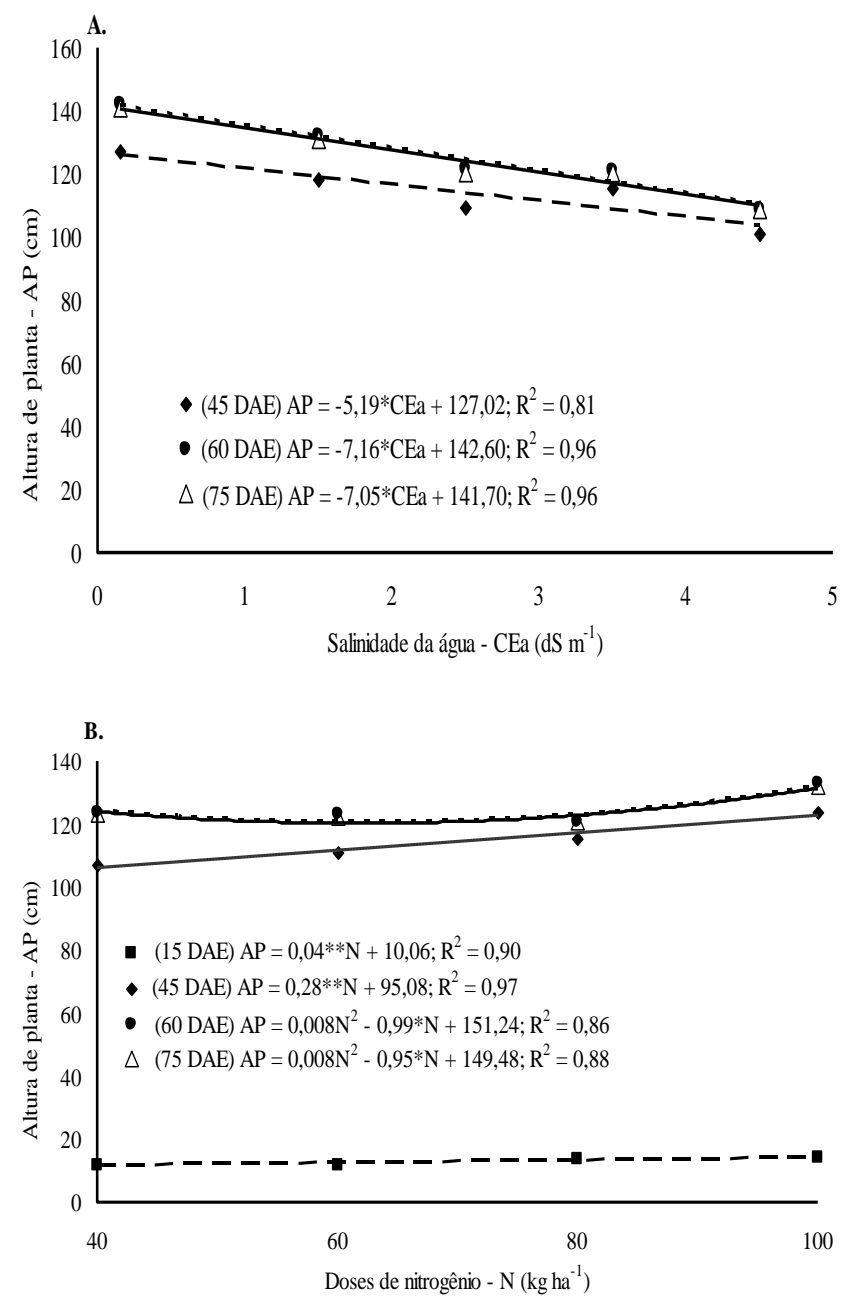

Figura 2. Altura de planta de girassol cv. EMBRAPA 122 V 2000 em função da salinidade da água de irrigação aos 45, 60 e 75 DAE (A) e da adubação nitrogenada aos 15, 45, 60 e 75 DAE (B).

Com base na análise de variância, a salinidade da água de irrigação exerceu efeito significativo no número de folhas aos 30 e 75 DAE e na área foliar em todas as épocas, exceto 
aos 15 DAE, enquanto que a adubação nitrogenada afetou de forma significativa o número de folhas aos 15 e 30 DAE e a área foliar em todas as épocas de avaliação, exceto aos 75 DAE. Com relação à interação entre os fatores salinidade da água de irrigação e doses de nitrogênio, observou-se efeito significativo $(\mathrm{p}<0,01)$ apenas para área foliar aos 15 DAE (Tabela 2).

Tabela 2. Resumo das análises de variância referentes a número de folhas e a área foliar de plantas de girassol, aos 15, 30, 45, 60 e 75 (DAE), em função da salinidade da água de irrigação e da adubação nitrogenada

\begin{tabular}{|c|c|c|c|c|c|}
\hline \multirow{2}{*}{\multicolumn{2}{|c|}{ Fonte de Variação }} & \multicolumn{4}{|c|}{ Quadrados Médios } \\
\hline & & \multicolumn{4}{|c|}{ Dias após a emergência (DAE) } \\
\hline & 15 & 30 & 45 & 60 & 75 \\
\hline \multicolumn{6}{|c|}{ Número de folhas } \\
\hline Salinidade (S) & $0,858^{\mathrm{ns}}$ & $8,833^{*}$ & $0,535^{\mathrm{ns}}$ & $2,681^{\mathrm{ns}}$ & $40,139^{*}$ \\
\hline Reg. Linear & - & $17,107^{*}$ & - & - & $117,861^{* *}$ \\
\hline Blocos & $3,079^{\mathrm{ns}}$ & $4,429^{\mathrm{ns}}$ & $0,579^{\mathrm{ns}}$ & $1,962^{\mathrm{ns}}$ & $36,037^{*}$ \\
\hline Resíduo 1 & 0,917 & 1,861 & 3,594 & 2,493 & 6,183 \\
\hline Nitrogênio (N) & $5,661^{* *}$ & $25,081^{*}$ & $6,977^{\mathrm{ns}}$ & $3,411^{\mathrm{ns}}$ & $3,570^{\mathrm{ns}}$ \\
\hline Reg. Linear & $16,803^{* *}$ & $63,020^{* *}$ & - & - & - \\
\hline Interação (S xN) & $0,855^{\mathrm{ns}}$ & $3,408^{\mathrm{ns}}$ & $2,321^{\mathrm{ns}}$ & $2,581^{\mathrm{ns}}$ & $7,456^{\mathrm{ns}}$ \\
\hline Resíduo 2 & 1,250 & 5,913 & 4,219 & 5,093 & 11,870 \\
\hline $\mathrm{CV} 1(\%)$ & 15,25 & $-\cdots$ & 8,48 & 7,63 & 14,56 \\
\hline CV $2(\%)$ & 17,79 & 12,03 & 9,18 & 10,90 & 20,18 \\
\hline \multicolumn{6}{|l|}{ Área foliar } \\
\hline Salinidade (S) & $4208,9^{\mathrm{ns}}$ & $1845610,3^{*}$ & $8095976,2^{* *}$ & $15143292,1^{* *}$ & $18196707,6^{* *}$ \\
\hline Reg. Linear & - & $4008923,7^{*}$ & $19905234,4^{* *}$ & $46123823,8^{* *}$ & $61643728,2^{* *}$ \\
\hline Blocos & $3989,4^{\mathrm{ns}}$ & $154045,5^{\mathrm{ns}}$ & $1439091,7^{\mathrm{ns}}$ & $1860045,8^{\mathrm{ns}}$ & $7737700,9^{\mathrm{ns}}$ \\
\hline Resíduo 1 & 1302,6 & 441529,5 & 1023703,4 & 1112184,5 & 1490574,6 \\
\hline Nitrogênio (N) & $24306,7^{* *}$ & $2523093,3^{* *}$ & $6705778,3^{* *}$ & $6167743,0^{*}$ & $7041778,5^{\mathrm{ns}}$ \\
\hline Reg. Linear & $71077,7^{* *}$ & $6872800,4^{* *}$ & $19802047,3^{* *}$ & $17985481,2^{* *}$ & - \\
\hline Interação (S x N) & $1912,5^{* *}$ & $481956,1^{\mathrm{ns}}$ & $1932185,6^{\mathrm{ns}}$ & $3398862,2^{\mathrm{ns}}$ & $2789291,4^{\mathrm{ns}}$ \\
\hline Resíduo 2 & 618,5 & 426422,1 & 1459928,9 & 2073744,0 & 3096998,5 \\
\hline - & $-\ldots$ & $-\ldots-\ldots$ & - & - & . \\
\hline CV $1 \quad(\%)$ & 24,5 & 27,1 & 19,5 & 17,6 & 21,8 \\
\hline CV $2 \quad(\%)$ & 16,9 & 26,6 & 23,3 & 24,0 & 31,4 \\
\hline
\end{tabular}

CV coeficiente de variação; ** significativo a $1 \%$ de probabilidade; $*$ significativo a $5 \%$ de probabilidade; ${ }^{\text {ns }}$ não significativo
Conforme as equações de regressão (Figura 3A) o aumento da salinidade inibiu linearmente o número de folhas do girassol com decréscimo de $1,66 \%(0,35)$ e $4,76 \%(0,92)$, por aumento unitário da condutividade elétrica da água de irrigação aos 30 e aos 75 DAE, respectivamente. Observa-se também que o número de folhas aos 70 DAE é menor que aos 30 DAE; essa redução pode está relacionada com o período de senescência das folhas.

A adubação nitrogenada estimulou linearmente a emissão foliar (Figura 3B) aos níveis de 25,8 e 15,8\% aos 15 e aos 30 DAE, nos intervalos de 40 a $100 \mathrm{~kg} \mathrm{ha}{ }^{-1}$ de nitrogênio. Nesses períodos foram aplicados apenas $2 / 3$ das doses de $\mathrm{N}$, sendo $1 / 3$ no semeio e a outra parte aos 20 DAE. Estes resultados estão coerentes com os de Oliveira et al. (2010) que concluíram que o aumento das doses de nitrogênio inibe os efeitos depressivos da salinidade no desenvolvimento inicial do girassol.

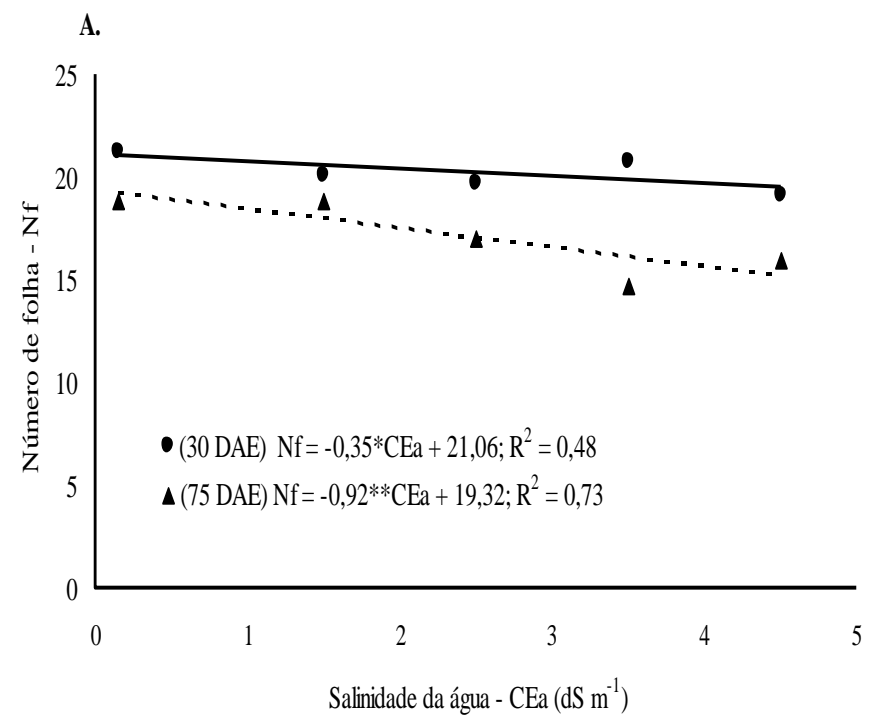


B.

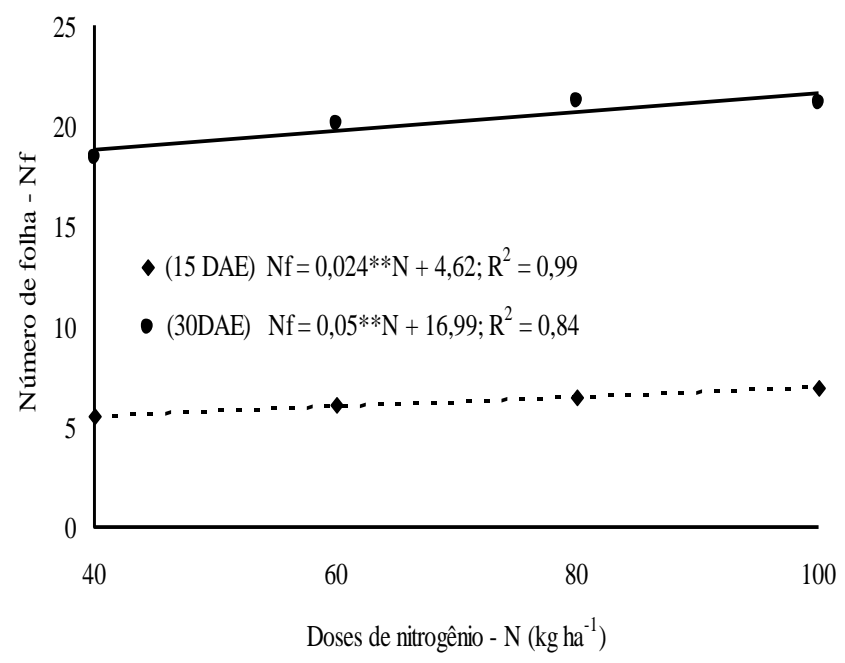

Figura 3. Número de folhas das plantas de girassol cv. EMBRAPA 122 V 2000 cultivado em função da salinidade da água de irrigação aos 30 e 75 DAE (A) e da adubação nitrogenada aos 15 e 30 DAE (B).

Assim como verificado para o número de folhas, o aumento da salinidade das águas de irrigação prejudicou também a área foliar do girassol (Figura 4A). Os valores decresceram em níveis de 5,93; 6,22; 7,82 e 9,26\% aos 30, 45, 60 e 75 DAE, respectivamente, por aumento unitário da salinidade da água de irrigação. Estes resultados estão de acordos com os obtidos por Silva et al. (2009), que observaram redução de $37 \%$ na área foliar das plantas irrigadas com água com salinidade $3,5 \mathrm{dS} \mathrm{m}^{-1}$ em relação as plantas irrigadas com água de salinidade 0,15 $\mathrm{dSm}^{-1}$. Segundo Tester e Davenport (2003), o decréscimo da área foliar das plantas em condições salinas pode estar relacionado com um dos mecanismos de adaptação da planta ao estresse salino, diminuindo a superfície transpirante. Desta forma, a redução da área foliar sob tais condições é importante para a manutenção do potencial hídrico elevado na planta, obtido através da diminuição na transpiração.
De forma análoga à de número de folhas, a adubação nitrogenada, promoveu maior área foliar com acréscimo de 1,08, 0,76 e 0,58\% aos 30, 45 e 60 DAE por aumento unitário das doses de nitrogênio (Figura 4B). Oliveira et al. (2010) estudando o efeito das fontes de nitrogênio, utilizando o sulfato de amônio na adubação da cultura do girassol, verificaram aumento na área foliar da ordem de 15,5 e 13,2\%.
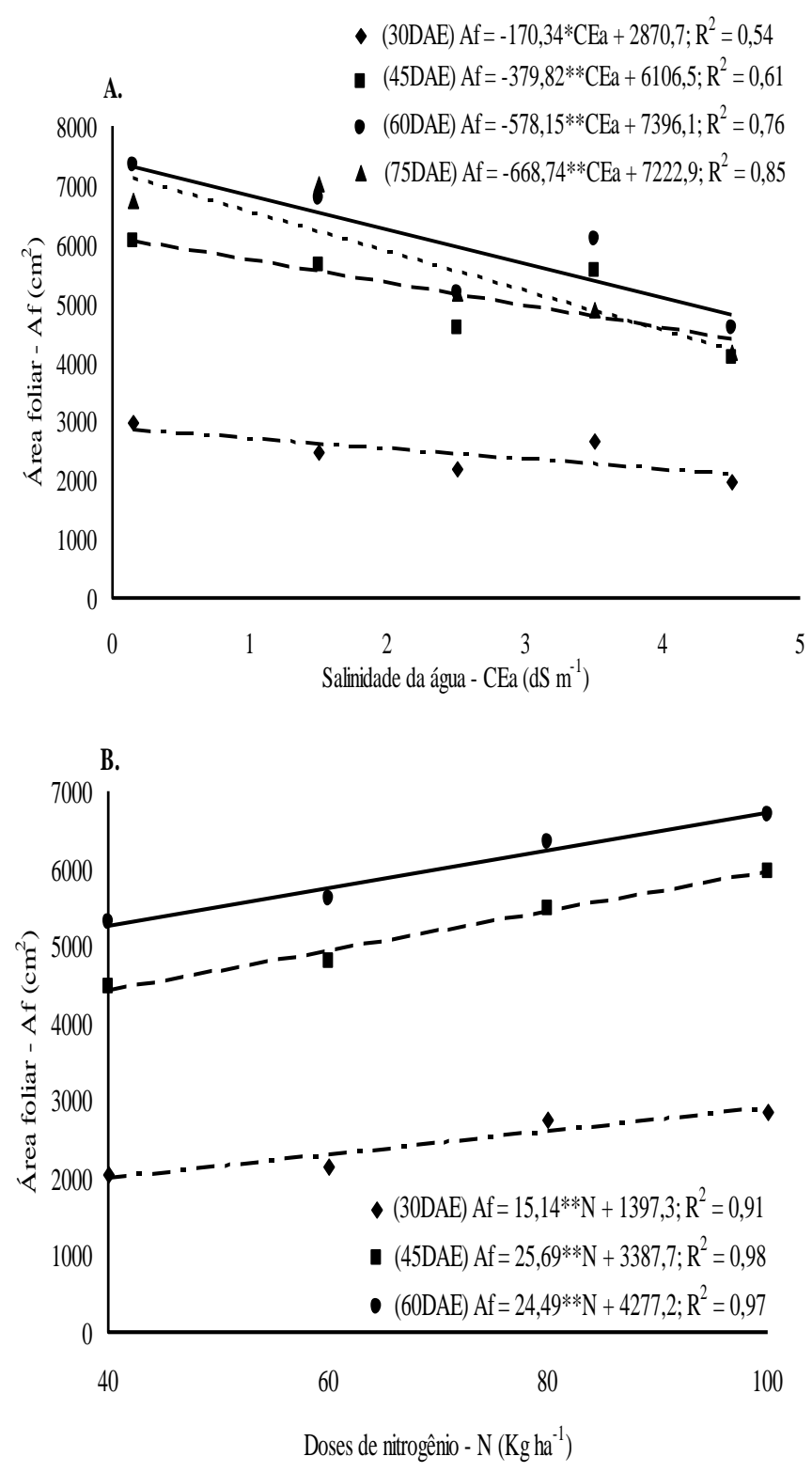

Figura 4. Área foliar das plantas de girassol cv. EMBRAPA 122 V 2000 em função da salinidade da água de irrigação aos 30, 45, 60 e 75 DAE (A) e da adubação nitrogenada aos 30, 45 e 60 DAE (B). 
O desdobramento do fator doses de nitrogênio dentro do fator salinidade da água de irrigação (Figura 5A) mostrou resultados significativos para as doses 80 e $100 \mathrm{~kg} \mathrm{ha}^{-1}$ de $\mathrm{N}$, de forma linear decrescente, de modo que a área foliar das plantas cultivadas com $100 \mathrm{~kg} \mathrm{ha}^{-1}$ de $\mathrm{N}$ foi maior comparada com aquela proveniente de plantas adubadas com $80 \mathrm{~kg} \mathrm{ha}^{-1}$ de $\mathrm{N}$, deixando claro que o nitrogênio atenua os efeitos da salinidade da água de irrigação.

Para o fator salinidade da água de irrigação dentro do fator doses de nitrogênio (Figura 5B), verificou-se que os níveis de salinidade 0,15 ; 1,$5 ; 2,5$ e $4,5 \mathrm{dS} \mathrm{m}^{-1}$ apresentaram resultados significativos de forma linear crescente. Observa-se que a área foliar das plantas adubadas com $100 \mathrm{~kg} \mathrm{ha}^{-1}$ de nitrogênio mostrouse superior à área foliar das plantas adubadas com $80 \mathrm{~kg} \mathrm{ha}^{-1}$ de $\mathrm{N}$, para todos os intervalos estudados da condutividade elétrica da água de irrigação, tendo em vista que nesse período de avaliação de 15 DAE foi aplicado apenas $1 / 3$ da adubação nitrogenada. Tendência inversa ocorreu para a área foliar das plantas em função do aumento dos níveis de salinidade de 0,15 para $4,5 \mathrm{dS} \mathrm{m}^{-1}$. Oliveira et al. (2010) estudando, em ambiente protegido, a interação entre salinidade e fontes de nitrogênio no desenvolvimento inicial da cultura do girassol, aos 40 DAS, não registraram efeitos significativos entre os fatores sobre a área foliar.
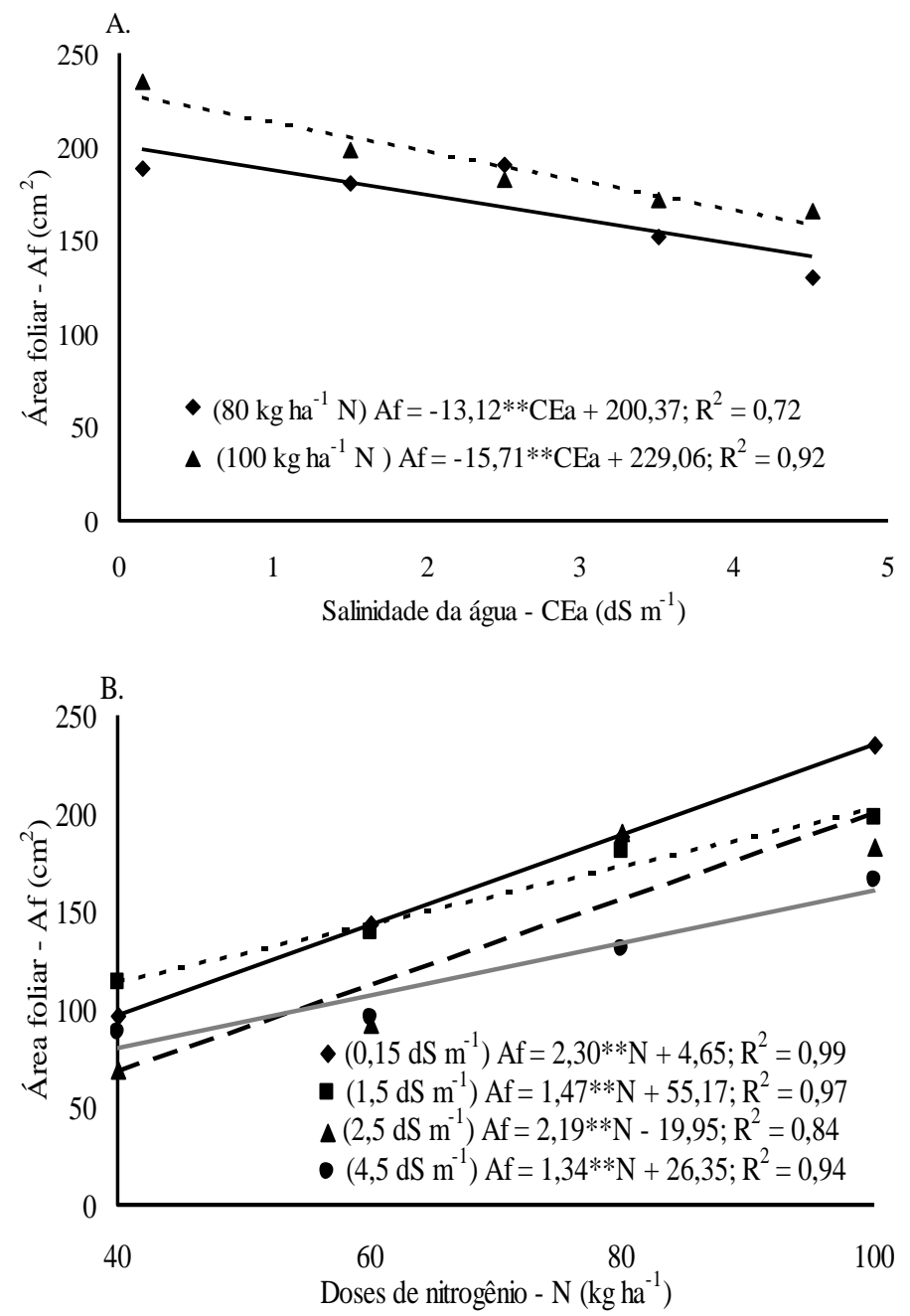

Figura 5. Desdobramento do fator doses de nitrogênio dentro do fator níveis de salinidade da água de irrigação (A) e do fator níveis de salinidade da água de irrigação dentro do fator doses de nitrogênio (B), correspondente a área foliar aos 15 DAE.

\section{CONCLUSÕES}

1. A altura da planta, o diâmetro caulinar, o número de folhas e área foliar do girassol cv. EMBRAPA 122 V 2000, são afetados de forma linear e negativamente pela condutividade elétrica da água de irrigação, sendo que, dentre 
as características agronômicas avaliadas, a área foliar foi a que se mostrou mais sensível à salinidade da água de irrigação;

2. A altura da planta, o diâmetro caulinar, o número de folhas e área foliar do girassol cv. EMBRAPA 122 V 2000 são afetados positivamente pela adubação nitrogenada;

3. O nitrogênio atenua o efeito da salinidade da água de irrigação sobre a área foliar de plantas de girassol cv. EMBRAPA 122 V 2000, aos 15 DAE, embora tenha sido aplicado até os 15 DAE apenas $1 / 3$ da dose total de N.

\section{AGRADECIMENTOS}

Agradecimento ao PNPD/CAPES pelo apoio financeiro.

\section{REFERÊNCIAS BIIBLIOGRÁFICAS}

ABBADI, J.; GERENDÁS, J.; SATTELMACHER, B. Effects of nitrogen supply on growth, yield, and yield components of safflower and sunflower. Plant and Soil, v.306, p.167-180, 2008.

ASHRAF M.; HARRIS, P. J. C. Potential biochemical indicators of salinity tolerance in plants. Plant Science, v.166, n.1, p.3-16, 2004.

AYERS, R. S.; WESTCOT, D. W. A qualidade da água na agricultura. 2.ed. Campina Grande: UFPB. 1999, 218p. Estudos da FAO, Irrigação e Drenagem, 29.

BISCARO, G. A.; MACHADO, J. R.; TOSTA, M. da. S.; MENDONÇA, V.; SORATTO, R. P.; CARVALHO, L. A. Adubação nitrogenada em cobertura no girassol irrigado nas condições de Cassilândia-MS. Ciência e Agrotecnologia, v.32, n.5, p.1366-1373, 2008.

CAVALCANTE, L. F.; REBEQUI, A. M.; SENA, G. S. A.; NUNES, J. C. Irrigação com águas salinas e uso de biofertilizante bovino na formação de mudas de pinhão-manso. Irriga, v.16, n.3, p.288-300, 2011.

DOORENBOS, J.; KASSAM, A. H. Efeito da água no rendimento das culturas. Campina Grande, UFPB, (Estudos FAO: Irrigação e Drenagem, 33), 306p, 1994.

EMBRAPA - EMPRESA BRASILEIRA DE PESQUISA AGROPECUÁRIA. Centro Nacional de Pesquisa de Solos. Manual de métodos de análise de solo. 2.ed. Rio de Janeiro, 1997. 212p.

FAGUNDES, J.D.; SANTIAGO, G.; MELLO, A.M.; BELLÉ, R.A.; STRECK, N.A. Crescimento, desenvolvimento e retardamento da senescência foliar em girassol de vaso: fontes e doses. Ciência Rural, v.37, n.4, p.987-993, 2007.

FERREIRA, D. F. Sisvar: versão 4.3. Lavras: DEX/UFLA, 2003. CD-ROM.

FLORES, P.; CARVAJAL, M.; CERDA, A.; MARTINEZ, V. Salinity and ammonium/nitrate 
interactions on tomato plant development, nutrition, and metabolites. Journal of Plant Nutrition, v.24, n.10, p.1561-1573, 2001.

FREIRE, A. L. O.; SOUSA FILHO, G. M.; MIRANDA, J. R. P.; SOUTO, P. C. S.; ARAÚJO, L. V. C. Crescimento e nutrição mineral do nim (Azadirachta Indica A. Juss.) e cinamomo (Melia azedarach linn.) submetidos à salinidade. Ciência Florestal, v.20, n.2, p. 207215, 2010.

IVANOFF, M. E. A.; UCHÔA, S. C. P.; ALVES, J. M. A.; SMIDERLE, O. J.; SEDIYAMA, T. Formas de aplicação de nitrogênio em três cultivares de girassol na savana de Roraima. Revista Ciência Agronômica, v.41, n.3, p.319-325, 2010.

MALDANER, I. C.; HELDWEIN, A. B.; LOOSE, L. H.; LUCAS, D. D. P.; GUSE, F. I.; BORTOLUZZI, M. P. Modelos de determinação não-destrutiva da área foliar em girassol. Ciência Rural, v.39, n.5, p.1356-1361, 2009.

MORGADO, L. N.; CARVALHO, C. F.; SOUZA, B.; SANTANA, M. P. Fauna de abelhas (Hymenoptera: Apoidea) nas flores de girassol Helianthus annuus L., em Lavras - MG. Ciência e Agrotecnologia, v.26, n.6, p.11671177, 2002.

MUNNS, R.; TESTER, M. Mechanism of salinity tolerance. Annual Review of Plant Biology. v.59, n.1, p.651-681, 2008.

NIVAS, D.; GOIKWAD, D. K.; CHAVAN, P. D. Physiological responses of two Morinda species under saline conditions. American
Journal of Plant Physiology, v.6, n.3, p.157-161, 2011.

NOBRE, R. G.; GHEYI, H. R; CORREIA, K. G.; SOARES. F. A. L.; ANDRADE, L. O de. Crescimento e floração do girassol sob estresse salino e adubação nitrogenada. Revista Ciência Agronômica, v.41, n.3, p.358-365, 2010.

OLIVEIRA, de F. de A.; OLIVEIRA, F. R. de A.; CAMPOS, de M. S.; OLIVEIRA, M. K. de T.; MEDEIROS, de J. F.; SILVA, O. da M. dos P. Interação entre salinidade e fontes de nitrogênio no desenvolvimento inicial da cultura do girassol. Revista Brasileira Ciências Agrárias. v.5, n.4, p.479-484, 2010.

RHOADES, J. D.; KANDIAH, A.; MASHALI, A. M.; Uso de águas salinas para produção agrícola. Campina Grande: UFPB. 2000. 117p. (Estudos da FAO, Irrigação e Drenagem).

RICHARDS, L. A. Diagnostico y recuperación de suelos salinos y sódicos. México, 1954. 172p. (Manual de Agricultura, 60).

SILVA, M. L. O.; FARIA, M. A.; MORAIS, A. R.; ANDRADE, G. P.; LIMA, E. M. C. Crescimento e produtividade do girassol cultivado. Revista Brasileira de Engenharia Agrícola e Ambiental. v.11, n.5, p.482-488, 2007.

SILVA, T. G. F.; ZOLNIER, S.; GROSSI, J. A. S.; BARBOSA, J. G.; MOURA, C. R. W.; MUNIZ, M. A. Crescimento do girassol ornamental cultivado em ambiente protegido sob diferentes níveis de condutividade elétrica de fertirrigação. Revista Ceres, v.56, n.5, p.602610, 2009. 
BIOMETRIA DO GIRASSOL EM FUNÇÃO DA SALINIDADE DA ÁGUA DE IRRIGAÇÃo E DA ADUBAÇÃo NITROGENADA

TESTER, M.; DAVENPORT, R. $\mathrm{Na}^{+} \quad$ plants. Annals of Botany, v. 91, n. 03, p. tolerance and $\mathrm{Na}^{+}$transport in higher 503-527, 2003. 